\title{
Woman with Fatigue, Shortness of Breath, and Chest Pressure
}

\section{Neilanjan Nandi MD, Sivakumar Srinivasan MD}

\section{Case Presentation}

A 62 year-old African American female with past medical history significant for scleroderma, Raynaud's phenomenon, and hypertension presented to the ED with 6 weeks of worsening fatigue, shortness of breath and a new onset of left sided chest pressure. Her outpatient medications included metoprolol $50 \mathrm{mg}$ every 12 hours and nifedipine XR 90 mg once daily. On physical examination, the patient was noted to have a blood pressure of $189 / 62 \mathrm{mmHg}$ and a pulse of 44 beats per minute. Her laboratory data including chemistry panel, complete blood count, and cardiac enzymes were unremarkable.

EKG was performed and the results are shown (Figures 1 and 2).

\section{Discussion}

In the spectrum of bradyarrhythmias, complete heart block represents a potentially life threatening condition frequently resulting in hemodynamic instability and death. Also known as third degree atrioventricular block $\left(3^{\circ} \mathrm{AVB}\right)$, this lethal arrhythmia is caused by a complete disconnect between the sinoatrial (SA) and atrioventricular (AV) nodes manifesting in independent atrial and ventricular rhythms. This dissociation is caused by a conduction system block at the level of the AV node, the Bundle of His, or the Purkinje bundle-branch system. Many etiologies have been identified causing $3^{\circ} \mathrm{AVB}$ (Table 1 ). Careful history taking and electrocardiographic analysis will allow appropriate emergent treatments to be intelligently executed.

Approximately $50 \%$ of AV block may be caused by conduction system fibrosis and sclerosis, otherwise known as idiopathic progressive cardiac conduction disease. Another $40 \%$ will be caused by either acute or chronic ischemic heart disease resulting in temporary, progressive, or permanent conduction system block.

\begin{tabular}{|c|c|}
\hline $50 \%$ & $\begin{array}{l}\text { Idiopathic Progressive Cardiac Conduction Disease } \\
\text { Lenegre's Disease - Slow progression to } 3^{\circ} \mathrm{AVB} \\
\text { Lev's Disease - Sclerosis \& calcification of left sided } \\
\text { cardiac tissues }\end{array}$ \\
\hline $40 \%$ & $\begin{array}{l}\text { Ischemic Heart Disease } \\
\text { Chronic Ischemic Disease } \\
\text { Acute } \mathrm{Ml}-20 \% \text { develop AVB }\left(8 \% \mathrm{w} / 1^{\circ} \mathrm{AVB},\right. \\
\left.5 \% \mathrm{w} / 2^{\circ} \mathrm{AVB}, 6 \% \mathrm{w} / 3^{\circ} \mathrm{AVB}\right)\end{array}$ \\
\hline $10 \%$ & $\begin{array}{l}\text { Drugs } \\
\text { Increased Vagal Tone } \\
\text { Valvular/Structural Disease - Aortic or Mitral valve } \\
\text { disease, HOCM } \\
\text { Developmental/Genetic - Congenital, Familial } \\
\text { Infiltrative - Restrictive Processes, Malignancy } \\
\text { Connective Tissue Disease - SLE, Scleroderma, } \\
\text { Infectious - Bacterial Endocarditis, Lyme Disease, Syphilis, } \\
\text { Chagas, Viral } \\
\text { Metabolic/Endocrine - Hyperthyroid, Myxedema, } \\
\text { Hyperkalemia, Hypokalemia } \\
\text { latrogenic }\end{array}$ \\
\hline
\end{tabular}

And a myriad of other causes exist that, although rare, should be considered in diagnosing and management of complete heart block. Toxicity from cardiac medications such as excess betablockade, calcium channel blockers (verapmil more than diltiazem), amiodarone, and Class I anti-arrhythmics (quinidine, procainamide) are not uncommon. Diffuse processes ranging from restrictive cardiomyopathies such as amyloidosis, sarcoidosis, and hemochromotosis to infiltrative malignancies such as Hodgkin's lymphoma and even multiple myeloma can cause 30 AVB. Infectious etiologies should not be overlooked as bacterial endocarditis, Chagas', and Lyme disease have been documented before. Electrolyte disturbances such as hyperkalemia and hormonal disturbances such as hyperthyroidism or myxedema coma may result in heart block as well. There are also congenital developmental abnormalities and familial genetic mutations of sodium channels (i.e. SCN5A, congenital long QT syndrome, Brugada syndrome) that have been identified. Iatrogenic complications after ethanol septal reduction or transcatheter closure of ventricular septal defects have been reported. Other exotic examples include neurodegenerative diseases, dermatomyositis, Paget's disease, and cardiac tumors.

Central to the mechanism of autoimmune rheumatic diseases (ARD) is the concept that these diseases are mediated via a systemic inflammatory state. Hence, it is not surprising that ARD's would contribute and promote atherosclerotic coronary artery disease. This, in turn, may lead to ischemic disease and myocardial inflammation creating an excellent substrate for cardiac arrhythmia and conduction disturbances to occur. Approximately $25 \%$ of patients with systemic sclerosis wre shown to have antibodies against cardiac tissue. Also, $67 \%$ of those with scleroderma were documented as having ventricular arrhythmias. About 25-75\% had abnormal ECG findings, bundle branch blocks, fasicular blocks, and less than $2 \%$ had $2^{\circ}$ or $3^{\circ}$ AVB.

Systematic ECG interpretation is always paramount. After appreciating that the $\mathrm{P}$ waves and QRS waves march out independently of one another on the rhythm strip, it is important to pay close attention to both the rate and morphology of the QRS complex. About $20 \%$ of $3^{\circ} \mathrm{AVB}$ are from a lesion at the level of the AV node and another $20 \%$ are within the bundle of His. Both lesions present with a narrow QRS complex junctional escape rhythm $(-45-60 \mathrm{bpm})$ and are generally hemodynamically stable. The remaining $60 \%$ of complete heart block are secondary to a lesion below the Bundle of His and manifest with a wide QRS escape rhythm $(<45 \mathrm{bpm})$ with hemodynamic instability.

Although some may be asymptomatic, symptoms may range from fatigue, light headedness, and dizziness to chest pain, syncopal event, dyspnea, mental status change, and of course, sudden cardiac death. Transcutaneous pacing is always indicated and temporary transvenous pacer may be placed as well. Emergently, atropine should be administered with caution. A wide QRS complex suggests infranodal block. Therefore, the anticholinergic 


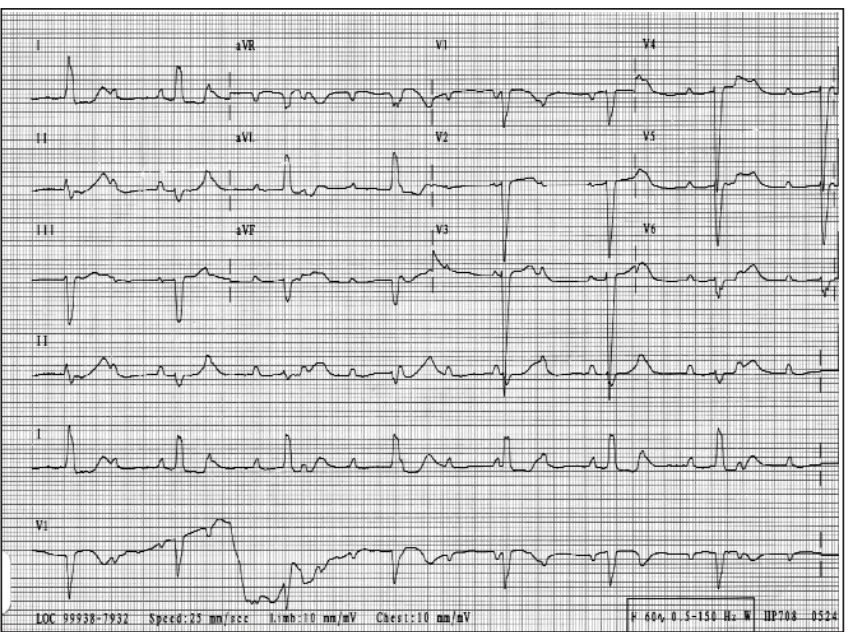

Figure 1: Complete heart block with ventricular escape rate of 44 bpm. Conduction via the left anterior fascicle with left posterior fascicular block (LPFB) \& RBBB.

effects of atropine will result in a relative vagolysis with subsequent unopposed sympathetic stimulation which only serves to increase the myocardial refractory period. This can dangerously exacerbate the complete heart block and further decrease the ventricular depolarizations and contractions leading to further hypotension and accelerate time to death.

\section{Conclusion}

The patient had a transvenous pacer placed emergently. After waiting a sufficient amount of time to rule out excess betablockade and calcium channel blockade, her heart block persisted and was attributed to progression of her scleroderma. A

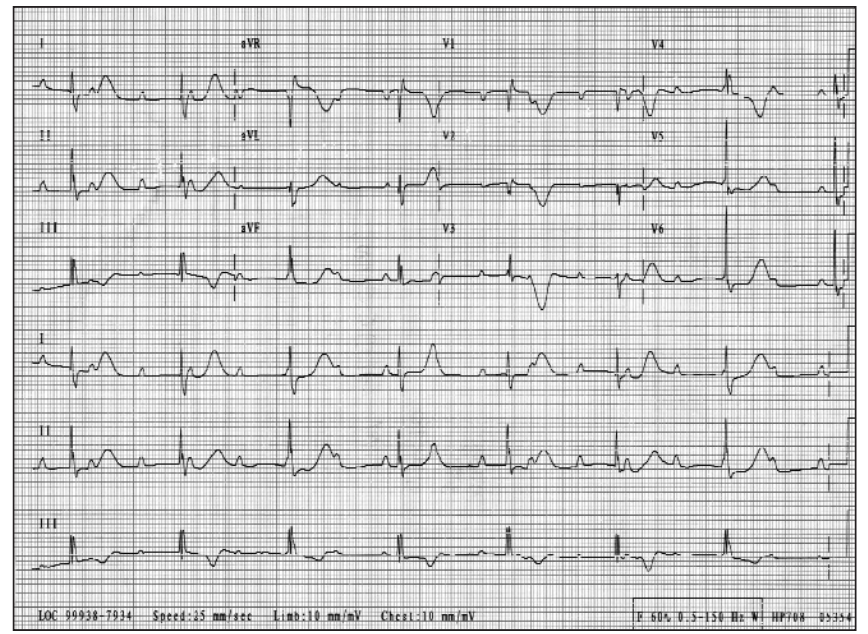

Figure 2: Obtained approximately 30 minutes after the initial EKG. Complete heart block with LBBB morphology. Escape rhythm originates above the Bundle of His bifurcation.

permanent pacemaker was promptly placed. Many etiologies exist to promote complete heart block. Autoimmune rheumatic diseases are no exception and may manifest as rhythm and conduction system disturbances resulting in sudden cardiac death. Electrocardiographic disturbances in autoimmune rheumatic diseases such as scleroderma are not insignificant and should be considered in the differential of complete heart block.

\section{References}

1. Mangrum JM, Dimarco JP. The evaluation and management of bradycardia. NEJM. 2000;342:703-709.

2. Seferovic PM, Ristic AD, Maksimovic R, et al. Cardiac arrhythmias and conduction disturbances in autoimmune rheumatic diseases. Rheum. 2006;45:iv39-iv42.

\section{When It Rains}

You ever stand in the rain,

Especially on a hot summers day,

And feel the rain drops drip from the top of your head,

Straight down till it soaks into the seams of your socks,

Do you remember pressing your foot down into your soggy shoe,

And feel bubbles flow between your toes,

And you just couldn't resist that puddle,

That giant, deep, dark brown, muddy puddle,

You just had to raise your knee high....

Then stomp down on that puddle with a force equal to that of Thor's lightning bolt,

You just had to do it,

Just had to,

You just couldn't waste a good puddle,

You just couldn't stay indoors,

Had too....just had to play in the rain...

My mother used to tell me the rain was God's tears,
The rain cooled you,

It played with you, watered you,

It surrounded you...fully,

It fed the trees, and filled the oceans,

You knew you were going to get wet...

You knew you were going to get sick...

You knew your mom was going to yell at you...

And that you were going to track muddy stains all over the floor...

You're going to get punished...

And it served you right.

You ruined your clothes,

Got yourself sick,

Messed up your hair,

Dirtied the house,

And you rejoiced in God's tears.

And you also knew.......

That you couldn't wait till the next rain shower.

Marshall Fleurant, MD 